\title{
Use of radiofrequency for the treatment of urinary incontinence in women: a systematic review
}

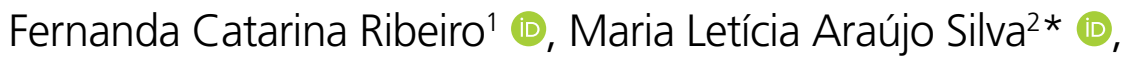 \\ Maria Amélia Pires Soares da Silva ${ }^{3}$ (1), Guilherme Pertinni de Morais Gouveia ${ }^{4}$ (1), \\ Laiane Santos Eufrásio³ (1), Maria Thereza Albuquerque Barbosa Cabral Micussi²
}

\section{INTRODUCTION}

Urinary incontinence (UI) is defined as involuntary loss of urine $^{1}$, affecting $25-45 \%$ of women, depending on the population ${ }^{2}$. Its classification is based on the pathophysiology and clinical condition of the patient, with the most common being urgency (UUI), stress (SUI), and mixed (IUM).

The SUI is characterized by the involuntary loss of urine due to a cough or physical exertion ${ }^{3}$. The etiology is multifactorial, which may be related to inadequate support and/or weakening of the pelvic floor muscles (PFM), deficiency in the closing mechanism of the urethral meatus, and reduction of collagen synthesis in the pelvic structures ${ }^{4,5}$. The dysfunction has social and psychological impacts, especially on the well-being of the individual. The main risk factors are age, obesity, menopause, pregnancy, parity, and type of delivery ${ }^{2}$.

The treatment varies and depends on the classification of incontinence, the patients' perception of symptoms, and their daily life habits ${ }^{6}$. According to the literature ${ }^{7,8}$, surgical techniques, drug therapy, and conservative treatments, such as PFM exercises and electrical stimulation, have been shown to improve UI symptoms. Currently, the search for alternatives and safe treatment methods with high cure rates are the targets of research to avoid surgical interventions. Radiofrequency (RF) therapy has been studied as a possible therapeutic modality for SUI, in addition to its increasing clinical use as a non-surgical and non-pharmacological treatment?

$\mathrm{RF}$ is a minimally invasive procedure involving the application of alternating current that creates electrical fields and generates heat by conversion only in the treatment area. Its frequency can vary from $30 \mathrm{kHz}$ to $300 \mathrm{MHz}$, and the energy emission mode depends on the number of electrodes, which can be monopolar, bipolar, tripolar, or multipolar ${ }^{10}$. RF can be used to treat SUI and MUI as it promotes submucosal collagen denaturation in the bladder neck and throughout the lower urinary tract, causing tissue retraction in these structures. Therefore, urinary symptoms are expected to be minimized as they are related to the pathophysiology of these types of incontinence ${ }^{8}$.

The search for treatment options that are quick to apply, less invasive, safe, and with fewer adverse effects has been growing rapidly, and this therapeutic modality is a good treatment option. Thus, this review highlights the effectiveness and complications of RF therapy for the treatment of UI in women.

\section{METHODS}

This systematic review was conducted from June 2020 to May 2021 by searching articles on the Web of Science, Lilacs, Scielo, PubMed, Cochrane, Pedro, Embase, Science Direct, CINAHL, and Scopus platforms. The following descriptors were used by combination: ["Woman" OR "Women"] AND ["Urinary Incontinence" OR "Urge urinary incontinence" OR "Stress Urinary incontinence"] AND ["Radiofrequency" OR "Radio Waves" OR "Pulsed Radiofrequency Treatment" OR "Radiofrequency Ablation" OR "Radiofrequency Therapy"].

The study population was composed of women with UI using any type of RF as an intervention, and there may be

\footnotetext{
'Universidade Federal do Rio Grande do Norte, Dermatology Department at the Naval Hospital of Natal - Natal (RN), Brazil.

Universidade Federal do Rio Grande do Norte, Department of Physiotherapy - Natal (RN), Brazil.

${ }^{3}$ Universidade Federal do Rio Grande do Norte, Faculty of Health Sciences of Trairi - Santa Cruz (RN), Brazil.

${ }^{4}$ Universidade Federal do Delta do Parnaíba - Parnaíba (PI), Brazil.

${ }^{\star}$ Corresponding author: marialetici29@gmail.com

Conflicts of interest: the authors declare there are no conflicts of interest. Funding: This study was conducted with the support of the Coordination for the Improvement of Higher Education Personnel - Brazil (CAPES) - Financing Code 001.

Received on July 27, 2021. Accepted on August 16, 2021.
} 
divergences between the studies related to cost and time of application. Regarding the comparison of treatments, there were no limitations, and the various treatments included no treatment, placebo, vaginal estrogen, or pelvic floor muscle training (TMAP).

The main outcome was the volume of urinary loss measured using the Pad test. Secondary outcomes were urinary loss measured by voiding diary and impact of UI on quality of life, which were assessed using validated International Continence Society questionnaires. Non-urinary variables, such as alterations related to the vaginal epithelium, vaginal dryness, and sexual function were also considered as secondary outcomes. The systematic review was conducted by two authors to select and evaluate the studies and by another to analyze the differences. The kappa test was performed to analyze the inter-rater agreement.

The following were included: clinical trials regardless of randomization and blinding and prospective studies conducted between 2016 and 2021, without language limitations. The exclusion criteria were as follows: studies with less than 3 months of intervention/follow-up; gray literature; animal and cytological studies; articles whose main objective was to evaluate the use of other types of energy for the treatment of UI; and articles aimed at rejuvenating vaginal, fecal incontinence, vaginal atrophy, and other urinary tract diseases.

The PARSIFAL platform was used to verify duplicate studies and the Mixed Methods Appraisal Tool (MMAT) in the 2011 version to assess the methodological quality of the articles.

\section{RESULTS}

A total of 279 articles were identified, of which 70 were duplicates and 181 were excluded after consideration by title and abstract. Six studies ( $\mathrm{n}=247$ women) were selected for final analysis (Figure 1). The inter-rater kappa test showed an agreement of $76 \%(\kappa=0.76 ; \mathrm{p}<0.001)$.

\section{Radiofrequency procedure}

The studies diverged regarding the devices, parameters, temperature, form of application, and number of sessions. It was observed that the monopolar $\mathrm{RF}^{11,12}$ and non-ablative ${ }^{13,14} \mathrm{RF}$ were the most used. Two studies ${ }^{11,12}$ used the Viveve system protocol (220 pulses of $90 \mathrm{~J} / \mathrm{cm}^{2}$ in the vaginal introitus). An article $^{13}$ used Spectra G2 Tonederm $^{\circledast}$, which applies a high frequency of $0.5 \mathrm{MHz}$. In the study using the Votiva device ${ }^{15}$, the parameters were adjusted according to the conditions of the volunteers. An article ${ }^{14}$ used the ThermiVa device without specifying the parameters. Another ${ }^{16}$ configured the device at $45 \mathrm{~W}$ and $4 \mathrm{MHz}$ to supply power to 64 microneedles, $0.2 \mathrm{~mm}$ in length, allocated in an area of $8 \mathrm{~mm} \times 8 \mathrm{~mm}$. Of the studies that specified the temperature, it ranged between $39-45^{\circ} \mathrm{C}^{13-15}$.

Two studies ${ }^{11,12}$ divided the treatment area into quadrants of the vaginal opening, with each quadrant having five consecutive pulse passages. One study applied RF to the external urethral meatus ${ }^{13}$, two ${ }^{14,15}$ applied in the vaginal canal and labia majora, and one ${ }^{17}$ in the urethral meatus and vaginal wall.

Regarding treatment sessions, two studies ${ }^{11,12}$ used one session for group I and two for group II, with an interval of 6 weeks; one study ${ }^{13}$ described a weekly application for 5 weeks; one study ${ }^{15}$ did not specify; and two others ${ }^{14,16}$ performed treatment every 30 days for three months. All studies performed follow-ups, ranging from 1 to 12 months ${ }^{11-16}$. These and other detailed information from the articles are shown in Table 1.

\section{Primary outcomes}

The volume of urinary loss was analyzed using the Pad test as the primary outcome ${ }^{11-13,16}$. Allan et al. ${ }^{11}$ showed in their 6-month study that the leakage volumes of the absorbent weight were similar between the randomized groups at the final assessment. The authors reported that $69 \%$ of the overall sample achieved a $>50 \%$ improvement in pad weight. In the second study ${ }^{12}$, with a 12-month follow-up, there was a difference between the randomized groups in relation to the weight loss of the pad, which was $>50 \%$. The group that received the two interventions showed a $54 \%$ improvement. In the group that received only one intervention, the evolution rate was $50 \%$.

The study by Lordelo et al. ${ }^{13}$ evaluated the individual evolution of each patient with a 1-h Pad test for three months. It was observed that $70 \%$ of the patients had a reduction in UI, $20 \%$ did not complain of additional loss, and $30 \%$ showed worsening of the additional loss.

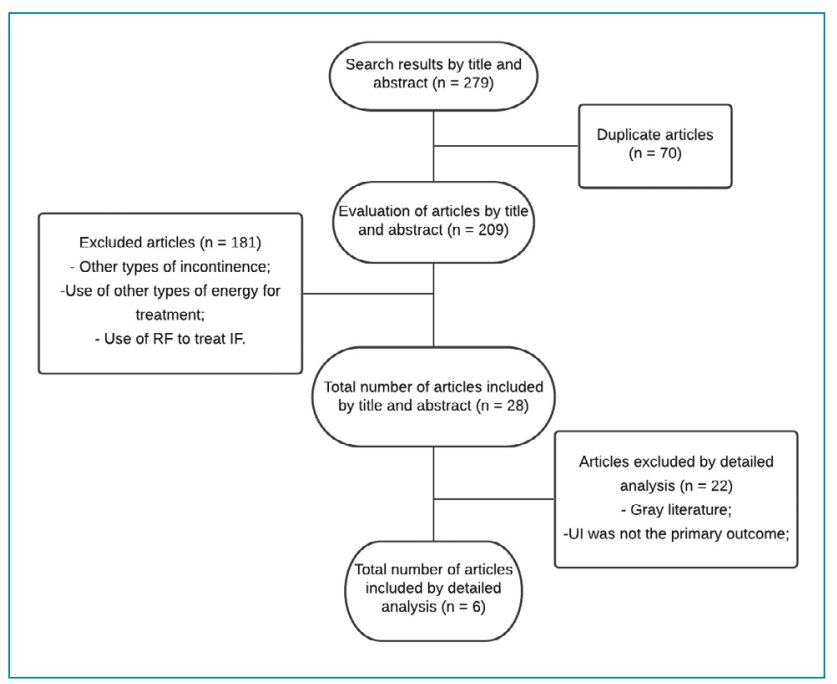

Figure 1. Flowchart of the study inclusion process. 


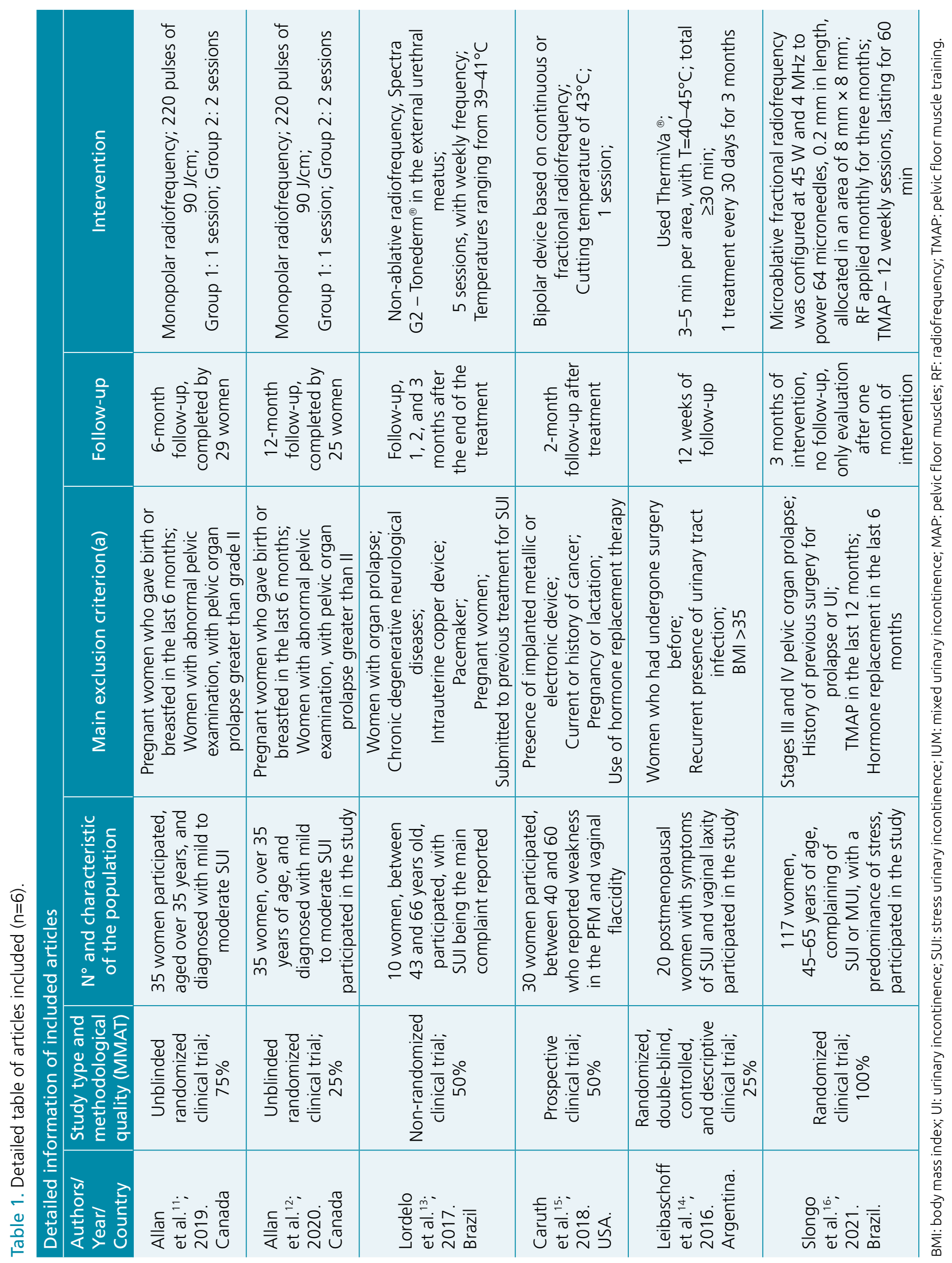


In contrast, another study ${ }^{16}$ found that the 1-h Pad test had a mean significant decrease of $7.22 \mathrm{~g}$ after treatment in all groups $(\mathrm{p}<0.001)$ but no differences between them $(\mathrm{p}=0.987)$. However, the authors did not justify why the results were similar.

\section{Secondary outcomes}

Secondary outcomes were divided into urinary and non-urinary variables. Among the urinary variables, the urinary loss was recorded by the voiding diary ${ }^{11,12}$, and the impact of UI on quality of life was evaluated using the following questionnaires: Incontinence Questionnaire-Urinary Incontinence Short Form (ICIQ-UI-SF) ${ }^{14-16}$, Incontinence Impact Questionnaire Short Form (IIQ-7) ${ }^{11,12,15}$, and Urogenital Distress Inventory (UDI-6) $)^{11,12,14}$.

In their first study, Allan et al. ${ }^{11}$ reported an $80 \%$ decrease in leakage episodes in both groups according to the 7-day voiding diary. A sustained improvement was observed for 6 months in relation to the subjective measures, based on the UDI-6, IIQ-7, and ICIQ-UI-SF questionnaires, compared to the initial assessment. In a second study ${ }^{12}, 64 \%$ of randomized subjects reported fewer episodes of leakage compared to that at the baseline. They also showed a decrease in UI symptoms and an improvement in quality of life through the UDI- 6 and ICIQ-UI-SF questionnaires.

Regarding the use of questionnaires, Slong et al. ${ }^{16}$ observed that there was a significant improvement between the groups in the evaluation of the ICIQ-UI-SF, highlighting a better result in the RF group with TMAP, which evolved from $13.6 \pm 3.8-8.2 \pm 5.2$.

In Caruth's study ${ }^{15}$, there was an improvement in the impact of UI $(62.7 \%)$ and quality of life $(64.6 \%)$ in the 2 -month evaluation using the IIQ-7 and ICIQ-UI-SF. Leibaschoff et al. ${ }^{14}$ observed a significant difference between the control $(17.3 \pm 0.78)$ and active $(11.4 \pm 0.66)$ groups in relation to the ICIQ-UI-SF. The UDI-6 also showed an improvement between groups (33.7 \pm 12.5 versus $16.2 \pm 6.0$ ).

The so-called non-urinary outcomes considered the effects of RF in relation to changes related to the vaginal epithelium, vaginal dryness, and sexual function. However, not all studies evaluated these parameters, but those that covered these variables used the vaginal health index $(\mathrm{VHI})^{14,16}$ and ICIQ Vaginal Symptoms Questionnaire (ICIQ-VS) ${ }^{15,16}$. Some studies included the impact of pelvic organ prolapse and the impact of anorectal and urinary symptoms on patients' quality of life, using the Pelvic Floor Impact Questionnaire (PFIQ-7) ${ }^{15}$.

To assess vaginal and sexual symptoms and quality of life, Leibaschoff et al. ${ }^{14}$ showed differences between the control group and the active group. There was a significant improvement in the active treatment group, from $11.5 \pm 0.67-19.3 \pm 2.01$, relative to VHI.

An author ${ }^{15}$ observed an improvement of $50.6 \%$ for vaginal symptoms, $72.1 \%$ for sexual issues, and $61.2 \%$ for pelvic floor impact on reassessment after 2 months of intervention in the ICIQ-VS and PFIQ-7 assessments. Other authors ${ }^{16}$ also found improvement in the ICIQ-VS after treatment in all groups, with the greatest improvement in the RF group (-9), followed by the RF+TMAP (-4.4) and TMAP groups (-3.4). The same authors also found improvement in vaginal moisture, fluid volume, vaginal $\mathrm{pH}$, and elasticity only in the RF and RF+TMAP groups but with no difference between them. It was also observed that the epithelial integrity improved in all groups and vaginal dryness improved in the RF group. In terms of VHI, the RF+TMAP (+3.2) and RF (+2.9) groups were superior to the TMAP group (+0.5). Regarding flaccidity, there was no significant difference between the groups.

\section{Adverse effects}

No serious or unexpected adverse effects were observed ${ }^{11-16}$. Lordelo et al. ${ }^{13}$ reported the presence of burning soon after the menstrual period in one patient; however, the physical examination did not show any change. Slongo et al. ${ }^{16}$ described that a participant in the RF group had mild vaginal burns with spontaneous improvement and mild dyspareunia after three months.

\section{DISCUSSION}

$\mathrm{UI}$ is a public health problem, with varied treatments. Of these, surgical treatment is an option, which may be associated with complications and recurrences ${ }^{17}$. Other therapies can be recommended according to the nature and intensity of the UI, such as TMAP, which is a conservative treatment option ${ }^{18}$. The growing search for safe, non-invasive, and effective alternatives has become increasingly popular, emphasized review studies like this.

RF therapy has been widely used to treat dermatological and gynecological conditions. The microablative fractional-type RF, which is used to improve skin, vaginal, and vulvar mucosal trophism ${ }^{19}$, results in promising responses in neocollagenesis and neoelastinogenesis ${ }^{20,21}$, consequently leading to clinical improvement. Thus, it is observed that this therapy provides a less invasive treatment for women with SUI and MUI ${ }^{11-16}$.

The importance of objective data evaluations is known, and thus, more accurate and coherent results can be obtained with the research. However, only four studies used the 1-h pad test to measure urine volume. Regarding secondary outcomes, two studies $^{13,16}$ evaluated PFM through digital palpation quantified by the modified Oxford scale. Another study ${ }^{14}$ performed the 
cytological analysis through a biopsy. Other studies ${ }^{11,12,15}$ performed the evaluation using questionnaires.

Importantly, the main objective of this review was to evaluate the application of RF in relation to urine loss and not factors related to intimate esthetics and sexuality. All studies addressed patients diagnosed with SUI, and only one ${ }^{17}$ included MUI in the sample.

Only two ${ }^{12,16}$ studies showed a longer period of intervention. It is believed that a short period of intervention may not be able to assess the expected changes in neocollagenesis and neoelastinogenesis ${ }^{20,21}$ and thus may not provide reliable results. Regarding sampling, most studies ${ }^{11-15}$ recruited a small number of volunteers, and only one had more than 100 patients in the sample ${ }^{16}$.

This review had some limitations. The studies that were included had low strength, lack of blinding, short post-intervention follow-up, and lack of clear description of randomization. Despite these limitations, it was observed that $\mathrm{RF}$ is an alternative therapy, proving to be effective and safe for the issues evaluated, which, according to the studies, is an alternative for the conservative management of patients with SUI.

\section{CONCLUSIONS}

The studies included in this review showed significant results of RF to resolve or minimize the complaints of women with SUI; however, according to the MMAT, the methodological quality of the studies was low. Therefore, more randomized, controlled, and blinded clinical trials are needed to provide safe therapy.

\section{AUTHORS" CONTRIBUTIONS}

MLAS: Investigation, Writing - review \& editing. MAPSS: Investigation, Writing - review \& editing. FCR: Formal Analysis, Writing - review \& editing. GPMG: Supervision, Writing review \& editing. LSE: Supervision, Writing - review \& editing. MTABCM: Supervision, Writing - review \& editing.

\section{REFERENCES}

1. Abrams P, Cardozo L, Fall M, Griffiths D, Rosier P, Ulmsten U, et al. The standardisation of terminology in lower urinary tract function: report from the standardisation sub-committee of the International Continence Society. Urology. 2003;61(1):3749. https://doi.org/10.1016/s0090-4295(02)02243-4

2. Milsom I, Altman D, Cartwright R, Lapitan MC, Nelson R, Sillén $\mathrm{U}$, et al. Epidemiology of Urinary Incontinence (UI) and other Lower Urinary Tract Symptoms (LUTS), Pelvic Organ Prolapse (POP) and Anal Incontinence (Al). In: Abrams P, Cardozo L, Khoury S, Wein AJ, editors. Incontinence: 5th International Consultation on Incontinence. 5th ed. Paris: ICUD-EAU. 2013. p. $15-107$

3. Haylen BT, Ridder D, Freeman RM, Swift SE, Berghmans B, Lee J, et al. An International Urogynecological Association (IUGA)/International Continence Society (ICS) joint report on the terminology for female pelvic floor dysfunction. Neurourol Urodyn. 2010;29(1):4-20. https://doi.org/10.1002/nau.20798

4. Long RM, Giri SK, Flood HD. Current concepts in female stress urinary incontinence. Surgeon. 2008;6(6):366-72. https://doi. org/10.1016/s1479-666x(08)80010-8

5. Fleischmann N, Flisser AJ, Blaivas JG, Panagopoulos G. Sphincteric urinary incontinence: relationship of vesical leak point pressure, urethral mobility and severity of incontinence. J Urol. 2003;169(3):999-1002. https://doi.org/10.1097/01. ju.0000051895.28240.12

6. Knorst MR, Royer CS, Basso DMS, Russo JS, Guedes RG, Resende TL. Avaliação da qualidade de vida antes e depois de tratamento fisioterapêutico para incontinência urinária. Fisioter Pesqui. 2013;20(3):204-9. https://doi.org/10.1590/ S1809-29502013000300002

7. Silva $\mathrm{L}$, Lopes $\mathrm{MH}$. Urinary incontinence in women: reasons for not seeking treatment. Rev Esc Enferm USP. 2009;43(1):72-8. https://doi.org/10.1590/s0080-62342009000100009
8. Hersh L, Salzman B. Clinical management of urinary incontinence in women. Am Fam Physician. 2013;87(9):634-40. PMID: 23668526

9. Boas AQV, Brasil C, Pavie MC, Damasceno L, Santos JM, Lordelo P. Radiofrequência não ablativa no tratamento da incontinência urinária de esforço. Rev Pesqui Fisioter. 2014;4(3):215-21. https://doi.org/10.17267/2238-2704rpf.v4i3.475

10. Bonjorno AR, Gomes TB, Pereira MC, Carvalho CM, Gabardo $M C L$, Kaizer $M R$, et al. Radiofrequency therapy in esthetic dermatology: a review of clinical evidences. J Cosmet Dermatol. 2020;19(2):278-81. https://doi.org/10.1111/jocd.13206

11. Allan BB, Bell S, Husarek K. Early feasibility study to evaluate the viveve system for female stress urinary incontinence: interim 6-month report. J Womens Health (Larchmt). 2020;29(3):383-9. https://doi.org/10.1089/jwh.2018.7567

12. Allan BB, Bell $S$, Husarek K. A 12-month feasibility study to investigate the effectiveness of cryogen-cooled monopolar radiofrequency treatment for female stress urinary incontinence. Can Urol Assoc J. 2020;14(7):E313-8. https://doi.org/10.5489/cuaj.6145

13. Lordelo P, Vilas Boas A, Sodré D, Lemos A, Tozetto S, Brasil C. New concept for treating female stress urinary incontinence with radiofrequency. Int Braz J Urol. 2017;43(5):896-902. https://doi.org/10.1590/S1677-5538.IBJU.2016.0621

14. Leibaschoff G, Izasa PG, Cardona JL, Miklos JR, Moore RD. Transcutaneous Temperature Controlled Radiofrequency (TTCRF) for the treatment of menopausal vaginal/genitourinary symptoms. Surg Technol Int. 2016;29:149-59. PMID: 27608749

15. Caruth JC. Evaluation of the safety and efficacy of a novel radiofrequency device for vaginal treatment. Surg Technol Int. 2018;32:145-9. PMID: 29791707

16. Slongo H, Lunardi ALB, Riccetto CLZ, Machado HC, Juliato CRT. Microablative radiofrequency versus pelvic floor muscle training 
for stress urinary incontinence: a randomized controlled trial. Int Urogynecol J. 2021. https://doi.org/10.1007/s00192-021-04758-2

17. Muniz ALP, Bilhar APM, Bezerra LRPS, Ribeiro ACM, Oliveira SC. Perfil epidemiológico e complicações cirúrgicas de mulheres submetidas a cirurgias para disfunção do assoalho pélvico em centro de referência do estado do Ceará, no período de 2014 a 2016. Rev Med UFC. 2019;59(4):27-33. https://doi. org/10.20513/2447-6595.2019v59n4p27-33

18. Brito FA, Gentilli RML. Desatenção à mulher incontinente na atenção primária de saúde no SUS. Fisioter Bras. 2017;18(2):20513. https://doi.org/10.33233/fb.v18i2.799

19. Kamilos MF, Aguiar LM, Batista VH, Roa CL, Aguiar FN, Soares Júnior JM, et al. Microablative fractional radiofrequency as a therapeutic option for vulvar lichen sclerosus: a pilot study. Clinics (Sao Paulo). 2021;76:e2567. https://doi.org/10.6061/ clinics/2021/e2567

20. Kamilos MF, Borrelli CL. New therapeutic option in genitourinary syndrome of menopause: pilot study using microablative fractional radiofrequency. Einstein (Sao Paulo). 2017;15(4):445-51. https://doi.org/10.1590/S167945082017A04051

21. Soares-Júnior JM, Barbosa MTA, Aguiar LM, Seganfredo IB, Pereyra EAG, Melo NR, et al. Energy-based devices in gynecology: the new frontier for the treatment of genitourinary syndrome of postmenopause? Clinics (Sao Paulo). 2021;76:e3066. https://doi.org/10.6061/clinics/2021/e3066 